\section{MIGRAÇÃO NO VOLEIBOL BRASILEIRO: A PERSPECTIVA DE ATLETAS E TREINADORES DE ALTO RENDIMENTO}

\author{
MIGRATION IN BRAZILIAN VOLLEYBALL: PERSPECTIVES OF HIGH- \\ PERFORMANCE ATHLETES AND COACHES
}

\author{
MIGRACIÓN EN EL VOLEIBOL BRASILEÑO: LA PERSPECTIVA DE ATLETAS Y \\ ENTRENADORES DE ALTO RENDIMIENTO
}

\begin{abstract}
Vanessa Silva Pontes*, Carlos Henrique de Vasconcellos Ribeiro**, Rafael Marques Garcia*, Erik Giuseppe Barbosa Pereira*
\end{abstract}

\begin{abstract}
Palavras chave:
Esportes.

Voleibol.

Migração.

Análise qualitativa.

Resumo: 0 objetivo deste estudo é analisar o discurso de atletas e treinadores de voleibol de alto rendimento sobre o processo de migração nesta modalidade, face às diversas conquistas das seleções, a espetacularização e a atratividade despertadas por esse esporte. A metodologia utilizada é descritiva e de natureza qualitativa, utilizando um roteiro de entrevista com treinadores e atletas das equipes Unilever/RJ e RJX/RJ. Como resultado, encontramos como categorias de análise para os treinadores as discussões sobre sua necessidade de encontrar bons atletas aliada à gestão financeira. Já para os jogadores, a experiência internacional, a distância da família e ascensão financeira e profissional são fatores que os fazem imigrar. Concluímos que os obstáculos encontrados pelos envolvidos abrangem principalmente aspectos culturais, econômicos e políticos.
\end{abstract}

Keywords:

Sports.

Volleyball.

Migration.

Qualitative Analysis.

Palabras clave:

Deportes.

Voleibol.

Migración.

Análisis cualitativo.

Abstract: This study looks into discourses of high-performance Brazilian volleyball athletes and coaches about the process of migration given the several achievements of Brazil's national teams as well as spectacularization and attractiveness aroused by that sport. The methodology is descriptive and qualitative, using an interview script with coaches and athletes of Unilever and RJX - volleyball teams from the state of Rio de Janeiro. As a result, we found discussions about coaches' needs to find good athletes coupled with financial management as categories of analysis for them. For players, in turn, international experience, distance from families and financial and professional rise are factors that cause them to migrate. We found that obstacles encountered by the people are mainly cultural, economic and political.

Resumen: El objetivo de este estudio es analizar el discurso de atletas y entrenadores de voleibol de alto rendimiento sobre el proceso migratorio en esta modalidad, frente a las diversas conquistas de las selecciones, el espectáculo y el atractivo que despierta este deporte. La metodología utilizada es descriptiva y de naturaleza cualitativa, usando un programa de entrevistas con entrenadores y atletas de los equipos Unilever/RJ y RJX/ RJ. Como resultado, encontramos como categorías de análisis para los entrenadores las discusiones sobre sus necesidades de encontrar buenos atletas y sobre la gestión financiera. En cuanto a los jugadores, la experiencia internacional, la distancia de la familia y la mejoría financiera y profesional son factores que los hacen emigrar. Llegamos a la conclusión de que los obstáculos encontrados por los implicados se refieren principalmente a los aspectos culturales, económicos y políticos.
*Universidade Federal do Rio de Janeiro. Rio de Janeiro, RJ, Brasil. E-mail: vanessaflu@ hotmail.com; rafa.mgarcia @ hotmail.com; egiuseppe@ eefd.ufrj.br

**Fundacão de Apoio à Escola Técnica. Rio de Janeiro, RJ, Brasil. E-mail: c.henriqueribeiro@ig.com.br

Recebido em: 28-07-2016 Aprovado em: 29-12-2017

DOI: http://dx.doi.org/10.22456/1982-8918.66495 (c) (1) (3) Licence 


\section{INTRODUÇÃOO}

A crise migratória internacional não é manchete apenas no cenário político e econômico dos jornais, estendendo-se também para as seções esportivas dos principais meios de comunicação de todo o mundo. Pela sua notoriedade, a migração é comumente apreciada no futebol, onde, segundo o estudo de Soares et al. 2011, os altos salários pagos no exterior, a maior visibilidade midiática e o maior prestígio junto aos torcedores/consumidores atraem jogadores em geral.

Há alguns anos, o Brasil deixou de ser um país receptor de imigrantes para se transformar em um país que fornece emigrantes para o mundo no campo esportivo, mais especificamente o futebol (RIAL, 2008). A autora compreende que a emigração de jogadores nesse esporte é multifatorial, mas que são os aspectos econômicos e sociais, aliados às condições de trabalho, os fatores principais para essa migração.

A primeira leva de emigração brasileira ocorreu na década de 1930, logo após a Copa do Mundo disputada no Uruguai, e teve como destino principal a Itália, terra de origem de muitos dos jogadores emigrantes.

Com a crescente movimentação de atletas estrangeiros, restrições foram impostas de forma legal e profissionalmente sobre os atletas brasileiros no exterior. No futebol, Tonini (2013) destaca que, em 1970, havia limitação no número de jogadores não naturalizados por clube no exterior e a abdicação da Seleção Brasileira por parte daqueles que se aventuravam em terras estrangeiras. Já no atletismo, com base nos estudos de Ribeiro et al. (2013), percebe-se que essa limitação também se faz presente sobre os corredores estrangeiros que vêm competir no Brasil. Dentre essas restrições, identificamos a necessidade de 0 atleta estrangeiro que se aventura pelo Brasil estar filiado oficialmente à Confederação de Atletismo de seu país, que deve obrigatoriamente apresentar uma autorização permitindo a sua participação nos eventos. Nas edições de corrida de rua brasileiras, ainda, os organizadores desses eventos devem enviar à Confederação Brasileira de Atletismo (CBAt) a cópia do convite feito ao atleta estrangeiro, para que a entidade autorize sua participação após averiguar sua regularidade (idem).

Na década de 1980, as portas para o estrangeiro abriram-se aos futebolistas oferecendo oportunidades ímpares para a carreira desses atletas. Tonini (op. cit.) destaca a desvalorização da moeda brasileira e o cenário atrativo que países como Reino Unido, Espanha, Alemanha, Itália e França exerciam sobre o bolso dos jogadores. Esses fatores dificultaram a manutenção dos atletas em território nacional. Países como Itália e Espanha, onde o futebol já havia alcançado nível de amadurecimento competitivo, eram os novos "eldorados" dos jogadores brasileiros. Apesar dos esforços de alguns clubes, os salários milionários pagos pelos clubes desses países, juntamente com os graves problemas econômicos e administrativos dos clubes brasileiros, acarretaram um êxodo futebolístico sem precedentes, principalmente pelo fato de a opção de jogar por um clube estrangeiro por algumas temporadas e retornar posteriormente à sua terra não ser mais visto de maneira negativa pelos compatriotas torcedores, dirigentes e jornalistas (SOARES et al., 2011).

O fenômeno da migração também pode ser constatado nas redes do voleibol. 0 processo de profissionalização do referido esporte em território brasileiro ocorreu entre as décadas de 1980 e 1990 com a persistência de Carlos Arthur Nuzman, que a essa altura era 
presidente da CBV. Através de sua proposta inovadora de associar empresas, clubes, atletas e mídia, deu liberdade às primeiras para patrocinarem os clubes e a seleção brasileira, que se destacava internacionalmente (MARCHI JUNIOR, 2001). Nesse cenário positivo, o voleibol nacional teve um salto qualitativo tanto em nível de competições quanto em surgimento de jogadores talentosos. $\mathrm{O}$ autor já destacava o voleibol como um dos esportes mais praticados no Brasil, devido às conquistas das seleções brasileiras e o aporte de patrocínio de grandes empresas, o que fortaleceu as competições nacionais, e reforça a atual posição das equipes masculina e feminina adultas do Brasil: $1^{\circ}$ e $3^{\circ}$ lugares, respectivamente (FÉDÉRATION INTERNATIONALE DE VOLLEYBALL, 2015).

A década de 1990 foi marcada pela saída de muitos atletas em direção ao exterior, fato que também aconteceu no voleibol brasileiro após as conquistas da Geração de Ouro, em 1992. O jornal Folha de S. Paulo, em 2001, lança uma matéria explicitando a crise pela qual passava o esporte brasileiro da última década, destacando a intensa emigração de jogadores do voleibol, basquete e futsal, chegando a citar, inclusive, os efeitos dessa crise nos campeonatos da Superliga de Voleibol, que perdeu grandes nomes nacionais e estrangeiros para clubes italianos (Lube Macerata, Trentino Volley, Pallavolo Modena e Torri Ferrara Volley) e nipônicos (NEC, Panasonic, Toray, Suntory e Toyota) durante esse período (LEISTER FILHO; LAJOLO, 2001).

O controle na movimentação de atletas de maneira geral apresenta certo gerenciamento, como no caso dos Estados Unidos, onde se utiliza o draft, uma espécie de recrutamento realizado pelas equipes de diversas ligas esportivas atendendo aos regulamentos próprios e específicos para a contratação de jogadores. No voleibol brasileiro, é o Ranking dos Atletas o documento que baliza as ações sobre a movimentação migratória dos atletas, conforme veremos a seguir.

Em 2014, o caso da atleta da seleção brasileira de vôlei Jaqueline encabeçou diversas páginas de jornal devido à polêmica gerada ante um sistema de pontuação estabelecido pela Confederação Brasileira de Voleibol (CBV) e que, diretamente, intermediou sua movimentação de um clube para outro. Mais recentemente, outra atleta, Elisângela, enfrentou o mesmo problema, tendo que optar pela transferência de clube.

Tais procedimentos de regulação entram em choque com a incursão estrangeira de atletas em suas buscas por reconhecimento profissional, retorno financeiro, melhores oportunidades e colocações no ranking internacional. No voleibol não é diferente, a exemplo da própria Superliga, que, sob determinada jurisprudência imposta pela CBV, restringe o número de estrangeiros a dois por equipe. Para tanto, utiliza-se de um sistema de pontuação individual e concede bonificações às equipes que repatriam brasileiros atuantes fora do país. A pontuação consiste na somatória dos pontos individuais dos atletas para formação das equipes, que deverão ter, no máximo, 40 pontos (masculino) e 43 pontos (feminino). Essa distinção entre acúmulo de pontos para equipes masculinas e femininas não está explicitada no documento de ranqueamento. Cada atleta recebe sua pontuação de acordo com o seu desenvolvimento técnico, e essa pontuação vai de 1 a 7 pontos (CBV, 2017), que é ratificada pelos representantes dos clubes, dos atletas e da própria CBV. Já as bonificações são gratificações concedidas aos atletas que 
tenha atuado no exterior e menos um ponto para cada temporada subsequente que tenha permanecido fora do Brasil, para a equipe que vier a contratá-lo (CBV, 2017, p.2).

A 16ª edição da Superliga (2009-2010) foi marcada pelo retorno de muitos brasileiros. Com uma competição organizada, de alto nível e visada por muitos atletas internacionais, os brasileiros viram a chance de retorno. A temporada contou com a repatriação de 43 atletas e estabeleceu o recorde de equipes participantes, com 30 times. Convém ressaltar, porém, que tais ordenações podem ter sido modeladas pela crise financeira mundial de 2008/2009, em que o Brasil mostrou razoável contraste à condição global neste período (CBV, 2015) .

Atualmente, as conquistas internacionais das seleções brasileiras, sejam com Bernardinho ou com José Roberto Guimarães, garantiram essa imponência nas quadras, sobretudo depois do bicampeonato olímpico feminino e das segundas colocações do masculino nos Jogos Olímpicos de 2008 e 2012. Outro fator a se considerar é a constante renovação das seleções, que mesmo com as trocas de seus principais jogadores, mantiveram o nível elevado.

No entanto, a migração de jogadores brasileiros atualmente suscita-nos questionamentos, visto que o vôlei brasileiro tem hoje, assim como as ligas russa, turca e italiana, um dos melhores campeonatos nacionais do mundo, mantendo sua competição com reconhecimento internacional (FÉDÉRATION INTERNATIONALE DE VOLLEYBALL, 2015).

Após o exposto, objetivamos analisar o discurso de atletas e treinadores de voleibol de alto rendimento sobre o processo de migração nessa modalidade.

Nosso estudo se justifica por ser, até onde se pode verificar, com base no levantamento das pesquisas sobre o fluxo migratório nos esportes, um dos pioneiros a analisar a migração de atletas no voleibol brasileiro. Socialmente, a pesquisa almeja disseminar o estudo dos processos migratórios dos atletas de alto rendimento. Entender os mecanismos em torno das relações entre o jogador e a comissão técnica, a mídia, o empresário e, principalmente, a visão do jogador sobre seu próprio futuro no esporte permeiam nossas análises e embasam nossos questionamentos sobre os motivos que os levam a proceder à emigração.

\section{METODOLOGIA}

Este estudo ${ }^{1}$ é de natureza qualitativa, utilizando como estratégia a Análise de Discurso. O modelo qualitativo proposto por Demo (2012) busca alastrar as possibilidades de analisar e perceber os fenômenos sociais, ao invés de fechá-los ou concluí-los. Já com relação à estratégia de análise, reportamos à Análise de Discurso. Nessa linhagem de pensamento, o discurso constitui-se em ordem de sentido entre/aos interlocutores, sendo integrante de um funcionamento social geral, isto é, a situação, o contexto social e histórico constitui o sentido empregado à sequência verbal proferida (ORLANDI, 2011; PÊCHEUX, 2014).

Como procedimentos de Análise do Discurso, nos inspiramos em Lima (1994), que adota as seguintes etapas para avaliar os discursos: 1- Descrição: "Retirada do discurso da fita cassete [sic] sem alterar uma única palavra [...]"; 2- Redução fenomenológica: na qual "o pesquisador julga mais significativas determinadas unidades e as destaca do discurso para análise. É a busca do essencial [...]. Isto é, frases revelatórias"; 3- Reorganização das 
unidades: após a 2ª etapa, "alguns discursos necessitam de uma reorganização das unidades, pois muitas delas convergem entre si, falam sobre o mesmo assunto, ainda são convergências dentro do próprio discurso" (LIMA,1994, p.64); 4- Interpretação fenomenológica: passada a 3ª etapa, realizamos a "transformação das expressões cotidianas [...] numa linguagem adequada, com ênfase no fenômeno que está sendo investigado" (LIMA,1994, p.64-65).

No que tange aos instrumentos, utilizamos um roteiro de entrevista semiestruturado contendo oito perguntas que versam sobre a temática em tela. Para Triviños (2009, p.152), a entrevista "[...] favorece não só a descrição dos fenômenos sociais, mas também sua explicação e a compreensão de sua totalidade, tanto dentro de sua situação específica como de sua situação de dimensões maiores".

A amostra, intencional, contou com a participação de dez entrevistados, sendo dois treinadores ${ }^{2}$ - Bernardinho (BE) e Marcelo Fronckowiak (MF) -, e oito atletas: Bruninho (BR), Leandro Vissoto (LV), Riad (RI), Vini (VN), Fofão (FF), Fabi (FB), a sérvia Brankica Mihajlovic (BM) e a canadense Sarah Pavan (SP). O número de entrevistados foi alcançado a partir do momento em que os pesquisadores chegaram a uma saturação discursiva, ou seja, os dados coletados apresentavam franca repetição, não sendo vislumbradas novas entrevistas. A escolha por esses personagens deu-se pelo caráter que representam no âmbito nacional e internacional, e por serem detentores dos títulos de suas equipes no período em tela. Ressaltamos que os treinadores entrevistados trabalham com grupos distintos de gênero em nível nacional: BE tem sua trajetória de treinador de equipes femininas enquanto MF se destaca com as equipes masculinas.

A fim de facilitar a compreensão dos resultados, realizamos uma filtragem nos discursos, selecionando trechos que envolviam nosso objeto do estudo. Os fragmentos retirados das entrevistas compõem uma sequência a se analisar, separados por categorias e relacionadas ao nosso material teórico.

Todos os nossos entrevistados experimentaram processos migratórios, ou seja, tiveram a experiência de emigrar tanto de uma cidade brasileira para outra, como tiveram a experiência de também jogar por um clube estrangeiro, à exceção de FB. Ainda, fatores como classe social, gênero, raça e etnia, tão sensíveis ao processo migratório, não podem ser desconsiderados, mas em nossa investigação ganham outros contornos nas falas dos entrevistados, uma vez que esses tendem a se ater às questões práticas de seu cotidiano, e que, por vezes, se tornam invisíveis, ou são colocadas em segundo plano.

\section{ANÁLISE DOS RESULTADOS}

\subsection{Mercado e posições técnico-táticas}

O voleibol é um esporte em que a posição dos jogadores em quadra é decidida desde cedo nas escolas de formação conforme aspectos antropométricos, tais como altura, envergadura, composição corporal, etc. Levantadores, ponteiros, opostos, por exemplo, são posições específicas e que demandam tempo para formação, treinamento e aprimoramento. Isso significa dizer que as equipes são compostas, invariavelmente, por determinado número

2 Bernardinho: técnico do Rexona/Ades/Unilever e da seleção masculina do Brasil; Marcelo Fronckowiak: ex-técnico da equipe masculina campeã do RJX e atual técnico da equipe Lebes/Gedore/Canoas (RS). 
de posições, com pouca margem de adaptação entre elas. Um ponto recorrente na composição das equipes, portanto, diz respeito às especificidades técnicas dos atletas. Jogadores que apresentam limitação são preteridos por treinadores brasileiros, o que faz do fluxo migratório um modulador das demandas do mercado da modalidade, isto é, as equipes priorizam a busca por jogadores que atendam às suas necessidades táticas e técnicas.

Partindo dessa lógica, $\mathrm{BE}^{3}$ afirma que:

[...] hoje nós temos no mundo, [...] carência de grandes levantadores, então certamente [pausa] todos querem, normalmente, ponteiros/passadores, [...] no mercado mundial [...] os times buscam jogadores com essas características. [...] Acho que, de um modo geral, a posição que menos atrai talvez seja a central [...] posição onde há uma menor migração [...].

Na edição 2013/2014 da Superliga, por exemplo, MF indicou ao RJX a contratação do levantador da seleção brasileira, Bruno Rezende. Sobre essa ocasião, o treinador adiciona:

[...] as posições mais valorizadas são as posições de ponteiro. Os ponteiros, aí depois eu diria opostos, junto com levantador, entendeu?' [...]. 'Já acontece um fenômeno engraçado, assim, que é [...]. Pra mim, o levantador é o cérebro do time, pra mim o levantador é o capitão do time, então eu baseei a minha indicação em cima desse jogador.

Os treinadores de voleibol costumam levar em consideração para a formação de suas equipes as suas necessidades em termos de posições táticas e técnicas. Aliado a isso, temos o fato de que bons ponteiros demoram longas temporadas para serem formados, assim como os levantadores. Nesse sentido, o fluxo migratório aparece como solução imediata para suprir demandas de posições muito específicas, de acordo com o momento em que uma vaga, ou até mesmo duas se abrem para a composição das equipes.

Assim, na formação de um atleta específico no alto rendimento do voleibol, ocorre que um jogador especialista em determinada posição pode ou não ser valorizado no mercado. Levantadores neste nível, por exemplo, são bem-vindos em qualquer equipe, porque estes, segundo Matias e Greco (2011), são os que lideram suas equipes em termos de definição tática.

Nas falas seguintes, vemos que a necessidade de contratação de jogadores valorizados esbarra no equilíbrio financeiro da equipe, ou seja, o mercado profissional do voleibol sofre com as questões de (des)valorização cambial, o que pode acarretar impedimentos no que diz respeito à boas aquisições. Entretanto, é enfatizado que os bons contratos não são descartados, indicando que a equipe estaria disposta a injetar recursos naqueles jogadores com maior probabilidade de render frutos ao grupo.

BE expõe: "[...] Isso aí é questão de mercado [...], depende de valores, depende de questão de moeda, e de ter um bom contrato".

MF acrescenta:

[...] É importante contextualizar, o euro tava numa relação muito melhor do que a que ele tá hoje, em termos de valorização, o euro praticamente valia 4 para 1 , entendeu, ficava mais fácil de contratar lá em específico, na França ${ }^{5}$, e tudo mais e foi uma forma de nós conseguirmos manter uma equipe competitiva, trazendo duas estrangeiras, no caso a Brankica e a Sarah Pavan.

3 Bernardo Rocha de Rezende, Rio de Janeiro, Brasil, 25 de agosto de 1959, treinador Unilever/RJ 2013-2014.

4 Marcelo Ricardo Fronckowiak, Porto Alegre, Brasil, 14 de março de 1968, treinador RJX/RJ 2013-2014.

5 Por seis temporadas, Marcelo dirigiu o Tourcoing Lille Metropole e o Harnes, na França. 
Em contrapartida, MF ainda menciona os pacotes de contratação, ou contratações múltiplas, como uma prática a ser enfrentada pelas equipes que almejam negociar um determinado jogador:

[...] se tu quiser contratar o Wallace, tu tem que contratar o fulano, beltrano $e$ sicrano. [...] Teruo é o principal agente esportivo do voleibol brasileiro, [...] ele tem a reserva de mercado dos ponteiros, então, cara, ele decide quais times vão ter tais e tais ponteiros.

Apesar disso, a participação de agentes esportivos é, para Bitencourt (2009), peça fundamental para fazer girar financeiramente o mercado, pois adequa a relação jogador/clube, favorecendo, assim, a circulação de atletas dentro do meio. 0 autor continua sua afirmação ao dizer que esses agentes conseguem bons contratos para jogadores atuarem em clubes de expressão e, dessas negociações, aqueles recebem tanto sobre as transações quanto sobre os salários dos atletas. Neste cenário, o agente - ou empresário - que tiver maior poder de oferta, de organização e de negociação será, sem dúvida, o dominante no mercado.

\subsection{Interesses e experiências pessoais}

Para melhor compreender a essência deste item, façamos uma observação nas ideias de Soca (2012, p.38): "La migración siempre es una situación social multicausal. La motivación de los migrantes deportistas es también compleja y multifacética ${ }^{6 "}$. Para o autor, a migração está relacionada com aspectos geográficos, culturais, econômicos, a presença de companheiros de seu país e o idioma. Outra causa dessa mobilidade é a possibilidade de gerar relações entre os clubes, o intercâmbio de atletas e de treinadores e a presença de agentes esportivos. Puentes et al. (2010) descrevem como "fatores de pressão" os mecanismos impostos por condições estruturais e que, em muitos casos, forçam e/ou incentivam os atletas a emigrarem.

Para além dessas causas de migração, Soca (2013) cita algumas discrepâncias envolvidas nesse processo. São elas: as disparidades salariais, a insegurança no trabalho em relação à capacidade do mercado para absorção de atletas e as diferenças sociais entre o envio e recebimento de países, fatores estes citados pelos entrevistados envolvidos nesta pesquisa.

Nas falas dos atletas e treinadores, percebemos que passar pela experiência de ser treinado por ícones internacionais é um dos motivos que fazem os atletas migrarem de seu país de origem, uma vez que essa estratégia está associada a uma ascensão na carreira de cada jogador, bem como melhores benefícios financeiros. BE contribui com essa assertiva quando expõe:

[...] muitas vezes um jovem atleta vem jogar no Brasil, que é uma liga de ótimo nível, tem ótimos treinadores, então os atletas vivem uma boa experiência no Brasil. Muitos deles amadurecem, crescem aqui [...]. A carreira de um atleta é uma carreira relativamente curta, portanto eles querem realmente obter, né, [...] conferir a maior renda possível para terem benefícios durante a carreira.

Em concordância com esse depoimento, o levantador da seleção brasileira, BR ${ }^{7}$, destaca:

[...] A gente tem uma carreira, vamos dizer assim, curta. Temos que aproveitar as oportunidades financeiras que a gente tem pra quando a gente tiver uma boa

6 Tradução: "A migração sempre é uma situação social multifatorial. A motivação dos desportistas que migram é completa e multifacetária".

7 Bruno Mossa de Rezende, Rio de Janeiro, Brasil, 2 de julho de 1986, voleibolista, levantador RJX/RJ 2013-2014. 
proposta a gente ir pra lá. E também pra jogar um novo desafio, né, um campeonato novo, então acho que acho que faz parte.

Esse discurso está em harmonia com a declaração de $\mathrm{R}^{8}$, que, quando questionado sobre quais fatores influenciaram em sua escolha, respondeu: "Foi, primeiramente, lógico, o lado financeiro. E segundo, por causa daquilo que eu falei, do campeonato ser um dos mais fortes do mundo e ter jogadores de um alto nível muito grande, campeões olímpicos mundiais [...]".

Embora a ida ao exterior de alguns jogadores não tenha sido movida pelo dinheiro, como o caso da atleta $\mathrm{FF}^{9}$, RI destaca que a questão financeira é determinante neste processo:

Antigamente, quando eu fui pra Itália, realmente, os salários estavam muito elevados, o euro tava muito alto então, assim, foi uma coisa que valeu muito a pena, apesar de não ter saído do país por dinheiro mesmo, foi por opção, mas eu acredito que o que atrai o jogador a sair do seu país com certeza é a parte financeira.

Acerca desse processo migratório internacional, Blanco (2000) nos faz saber que tal fenômeno nos esportes só assume o nível de globalização quando observadas três diretrizes: primeiro, a migração esportiva não é um fenômeno emergente; segundo, verifica-se o crescimento em todos os aspectos que envolvem a migração internacional nos esportes; terceiro, a migração nos esportes globalizados tem contribuído para o desenvolvimento da carreira profissional e internacional e a aquisição de resultados significativos em seu país de origem.

A partir dessa constatação, confere-se que muitos atletas vêm, outros vão e, ainda, alguns optam por permanecer na mesma equipe, fato este comprovado por $\mathrm{FB}^{10}$ :

Eu queria jogar aqui, era um sonho jogar na Unilever pra mim [...] moro na minha casa, tô perto dos meus amigos [...]. Lógico que a parte financeira pesa muito, mas a satisfação pessoal, [...] estar perto dos meus amigos, tá na praia, eu acho que eu priorizei muito mais o bem-estar do que só o dinheiro, mas algumas coisas pra mim não têm muito valor financeiro, é mais a satisfação pessoal.

A permanência do atleta em uma mesma equipe seria, também, de grande valia para os clubes brasileiros, uma vez que esses seriam bonificados com pontuação individualizada segundo o regulamento da CBV. Logo, a permanência de atletas formados nos clubes pode ser interpretada como uma estratégia pessoal que vai ao encontro dos interesses dos clubes.

É inegável, porém, que através desse "intercâmbio" profissional os envolvidos adquirem certa experiência e conhecimento em diversos aspectos, sejam eles profissionais, culturais e sociais, sendo, inclusive, defendido por alguns atletas, como SP11: "Eu acho que morar em outro país é uma experiência que todo mundo precisa provar. Tentar morar numa cultura diferente não é fácil, mas você aprende muito do mundo e é muito importante".

Sendo assim, questionamos os entrevistados sobre essa atuação fora do país. BE revela:

[...] foi uma experiência muito enriquecedora, sob todos os aspectos: de conhecer uma cultura diferente, de conhecer um tipo de atleta diferente, de conhecer um campeonato muito organizado e um pouco diferente do nosso [se referindo à Itália], então tudo isso pra mim foi certamente uma experiência enriquecedora na minha carreira de treinador. 
Quando interrogado sobre um possível retorno ao exterior, ele declara: "[...] o apoio da Unilever é uma coisa incrível, a gente se sente sim parte de uma grande família, então... Eu tô muito feliz onde eu tô. Então não é uma coisa que me atraia nesse momento [...]".

MF destaca como fundamental o fator de adaptação: "[...] quando a gente tem vontade de fazer um trabalho de excelência, de qualidade, a gente tem que se adaptar ao meio [...]".

Ao ser questionado sobre seu retorno ao Brasil, MF suscitou:

[...] eu já tava conversando com a minha mulher já fazia um tempo, o nosso filho mais novo ia fazer 6 anos, né, seria o momento de entrar na escola básica, fundamental aqui no Brasil. 0 meu nome, profissionalmente, começava a ser esquecido, outros já estavam surgindo, entendeu? As pessoas já não lembravam muito de mim e 0 Minas era uma bela de uma oportunidade em um clube extremamente estruturado $[\ldots]$.

Já nacionalmente, estar diante de uma nova oportunidade influenciou na sua transição do Minas para a equipe do RJX, tornando-se assim fator motivacional nesse processo: "[...] Eu tô feliz com a proposta, vou dirigir Lucão, Bruninho e companhia, entendeu? Então acho que o desafio profissional é grande [...]", e ainda destacou que: "[...] tem muita gente hoje que se interessaria em trabalhar com a gente, [...]". Ele revela que os atletas comentam "Seria legal trabalhar contigo, gostaria muito de trabalhar contigo, você é um cara que, ao longo dos anos mostra uma qualidade de trabalho legal".

Analisando todos os discursos, pudemos perceber que o aspecto cultural e a relação familiar são fatores muito determinantes nesse processo. Esses indicativos ficam ainda mais evidentes na fala de MF:

[...] há 10 anos atrás, 7 anos atrás, jamais viria morar no Rio. Por tudo que o Rio representava de negativo na cultura brasileira. [...] Sempre que eu tomei decisões na minha vida profissional, elas estiveram ligadas à minha família. Inclusive, nesse momento, eu tô tomando uma decisão... Eu tomei uma decisão de rejeitar propostas e de não sair, porque a minha família tá muito bem. [...] fica muito difícil você a cada dois anos estar mudando. Refazendo amigos, o círculo de amizades $[\ldots]$.

Encontramos, ainda, dificuldades decorrentes desta jornada migratória. LV ${ }^{12}$ cita a distância e comenta sobre o processo de adaptação: "[...] realmente, a gente sente a distância, né, de casa. Mas depois de um ano já estava bem adaptado e depois comecei a viver lá fora [Itália] tranquilamente, retornaria sem problema nenhum".

SP destaca a importância de se ter alguém por perto, no caso, seu cônjuge:

[...] estou aqui com meu marido, ele mora aqui comigo e eu já joguei sem ninguém, sozinha, e é muito difícil. Não tem amigos, não tem família. Todo mundo que joga aqui [Brasil], os nacionais, tem uma vida à parte do vôlei, mas pra estrangeiros é difícil, porque a vida é aqui, com vôlei. Mas, morar com meu marido a vida é muito mais fácil agora.

O idioma também se apresenta como empecilho em alguns casos, como o de FF:

[...] nunca é fácil, né, porque você vai pra outro país, com uma outra língua, né, outras culturas diferentes. Você tem que se adaptar, né, ao país que você tá indo, você tem que respeitar as regras, como funciona cada país e isso às vezes é difícil pra gente.

12 Leandro Vissotto Neves, Rio de Janeiro, Brasil, 30 de abril de 1983, voleibolista, oposto RJX/RJ 2013-2014. 
Ela cita que a ajuda de terceiros é primordial no processo de adequação: "[...] a gente consegue superar as dificuldades, a gente consegue encontrar pessoas que também ajuda [sic] a gente, consegue encontrar um brasileiro que às vezes mora no país que consiga também dar uma assistência [...]".

Nesses discursos, podemos perceber como fatores de ordem social, de gênero, de raça e de etnia estão presentes nas falas dos entrevistados através do reconhecimento de que a experiência internacional é, em geral, proveitosa aos aspectos profissionais e pessoais dos atletas. Aprendizagem de um idioma estrangeiro, bem como assimilação de uma cultura distinta, passam a ser indicadores de valia pessoal. Além disso, circular por um país estrangeiro parece não ser um problema de grande proporção, uma vez que jogadores atuantes em clubes brasileiros já se encontram longe de sua cidade natal.

\section{CONSIDERAÇÕES FINAIS}

Atualmente, o voleibol brasileiro é uma referência internacional em todos os aspectos que envolvem seu desenvolvimento, desde o centro de treinamento tático, técnico, físico e fisiológico até o acompanhamento com nutricionistas e fisioterapeutas, além de outros fatores. Essa menção é fruto principalmente de conquistas expressivas que a modalidade tem alcançado país afora, fato este responsável por atrair cada vez mais o interesse de atletas e treinadores ao redor do mundo.

Os fatores que influenciam de forma direta o fluxo migratório dos atletas se apresentam como a necessidade de desenvolvimento profissional - através do reconhecimento via ascensão social permitida por melhoria salarial, bem como desenvolvimento de suas qualidades técnicas, ou seja, experiência e maturidade como atleta. Além desses, a questão pessoal de conhecer outros países e culturas também é levada em conta nessas escolhas. Para os atletas de alto rendimento, atuar por outras equipes no estrangeiro pode ser mais uma forma de somar experiências e engrandecer o currículo pessoal e profissional.

0 mercado do voleibol, assim como outros, está atrelado à valorização financeira, ao interesse pessoal e a uma complexa rede de agentes esportivos. Nesse cenário, a figura do agente surge como peça chave na movimentação de atletas, uma vez que é o principal dinamizador desse processo. Através da demanda e oferta no mercado, ele organiza, (re) negocia e celebra acordos de transferência conforme a relação estabelecida entre jogador/ clube, utilizando-se de sua constante rede de contatos e influência para tal. Já aos atletas, compete-lhes a decisão de escolha, onde os aspectos culturais, sociais e familiares são fundamentais no que tange à duração de suas estadias além-mar.

Sugerimos, portanto, a continuidade dos estudos que envolvam não apenas os atletas de alto rendimento, mas também outros com distintos níveis técnicos. São inúmeras as possibilidades de investigação que envolvem atletas que circulam ao redor do mundo, em ligas pouco conhecidas. Há ainda a possibilidade de estudos sobre o processo de assimilação que culminem com absorção de um atleta por outra seleção. Recomendamos, também, a escolha de instrumentos alternativos de produção de dados, utilizando, por exemplo, a análise dos contratos entre atletas e clubes e dos sistemas de ranqueamento com o intuito de aprofundar as análises e entendimentos de como esse processo se desenvolve nas quadras de voleibol. 


\section{REFERÊNCIAS}

BLANCO, Cristina. Las migraciones contemporáneas. Madrid: Alianza, 2000.

CBV. CONFEDERAÇÃO BRASILEIRA DE VOLEIBOL. História do Voleibol. Disponível em: $<$ http://www.cbv.com.br/v1/institucional/histvolei.asp>. Acesso em: 14 ago. 2015.

CBV. CONFEDERAÇÃO BRASILEIRA DE VOLEIBOL. Ranking Oficial de Atletas. Superliga Masculina 2017/2018. Disponível em: <http://superliga.cbv.com.br/arquivos/TEXTO-OFICIALRANKING-SL-MASC-2017-2018.pdf >. Acesso em: 3 out. 2017.

DEMO, Pedro. Pesquisa e informação qualitativa: aportes metodológicos. 5. ed. Campinas: Papirus, 2012.

DIMEO, Paul; RIBEIRO, Carlos Henrique de Vasconcellos. I Am Not A Foreigner Anymore: A Micro-Sociological Study of the Experiences Of Brazilian Futsal Players In European Leagues. Movimento, v. 15, n. 2, p.1-9, 2009.

FARIA JR., Antonio Gomes. Pesquisa em Educação Física: enfoques e paradigmas. In: FARIA JR.; FARINATTI, Paulo de Tarso Veras (Orgs.). Pesquisa e produção do conhecimento em educação física: livro do ano de 1991/ SBDEF. Rio de Janeiro: Ao livro Técnico, 1992. p. 13-33.

FÉDÉRATION INTERNATIONALE DE VOLLEYBALL. FIVB Volleyball World Ranking Women. FIVB, 6 oct. 2015. Disponível em: < http://www.fivb.org/en/volleyball/VB Ranking_W_2015-10.asp >. Acesso em: 15 dez. 2015.

LEISTER FILHO, Adalberto; LAJOLO, Mariana. Crise motiva migração de atletas do Brasil ao exterior. Folha de S. Paulo, São Paulo, 4 jul. 2001. Seção Administração. Disponível em: < http://www1.folha.uol.com.br/fsp/esporte/fk0407200122.htm >. Acesso em: 13 mar. 2013.

MARCHI Jr., Wanderley. "Sacando" o voleibol: do amadorismo à espetacularização da modalidade no Brasil (1970 - 2000). 2001. 282 f. Tese (Doutorado) - Departamento de Educação Física, Universidade Estadual de Campinas, Campinas, 2001.

MATIAS, Cristino Julio Alves da Silva; GRECO, Pablo Juan. De Morgan ao voleibol moderno: o sucesso do Brasil e a relevância do levantador. Revista Mackenzie de Educação Física e Esporte, v. 10, n. 2, p. 49-63, 2011.

ORLANDI, Eni Pulcinelli. A linguagem e seu funcionamento: as formas do discurso. 6. ed. Campinas: Pontes, 2011.

PÊCHEUX, Michel. 0 discurso: estrutura ou acontecimento. 5. ed. Tradução Eni Orlandi. Campinas: Pontes, 2014.

PUENTES, Ruben et al. Towards an assessment of migration, development and human rights links: conceptual framework and new strategic indicators. In: GLOBAL FORUM, 4., 2010. México: Peoples' Global Action on Migration, Development, and Human Rights, 2010.

RIAL, Carmen Rodar: A circulação dos jogadores de futebol brasileiros no exterior. Horizontes Antropológicos, v. 30, n. 14, p.21-65, jul/dez. 2008.

RIBEIRO, Carlos Henrique Vasconcellos et al. Tem um queniano correndo entre nós: atletismo e migração no Brasil. Revista Brasileira de Educação Física e Esporte, v. 27, n.3, p.401-410, jul./set. 2013. 
RODRIGUES, Francisco Xavier Freire. 0 Fim do Passe e a Modernização Conservadora no Futebol Brasileiro (2001-2006). 2007. 345 f. Tese (Doutorado) - Programa de Pós-Graduação em Sociologia, Instituto de Filosofia e Ciências Humanas, Porto Alegre, 2007.

RODRIGUES, Francisco Xavier Freire. O fim do passe e as transferências de jogadores brasileiros em uma época de globalização. Sociologias, v. 24, n. 12, p.338-380, maio/ago. 2010.

SANTOS FILHO, José Camilo; GAMBOA, Silvio Sánchez (Orgs.). Pesquisa educacional: qualidade-quantidade. São Paulo: Cortez, 1997.

SOARES, Antonio Jorge Gonçalves et al. Jogadores de Futebol no Brasil: Mercado, Formação de Atletas e Escola. Revista Brasileira de Ciências do Esporte, v. 33, n. 4, p.905-921, out./ dez. 2011.

SOCA, Dante W. Steffano. Deporte y migración: aportes para su comprensión desde el caso uruguayo. Revista da ALESDE, v. 2, n. 2, p.33-43, out. 2012.

TONINI, Marcel Diego. "Ahhh, no estrangeiro, você é sempre estrangeiro": reflexões sobre a e/ imigração de futebolistas brasileiros e o racismo no futebol europeu a partir de uma entrevista com o ex-atleta Paulo Sérgio. Esporte e Sociedade, v. 8, n. 21, p. 1-28, mar. 2013.

TRIVIÑOS, Augusto Nibaldo Silva. Introdução à pesquisa em ciências sociais: a pesquisa qualitativa em Educação. 5. ed. São Paulo: Atlas, 2009. 